\title{
INTERDISCIPLINARIDADE E TRANSVERSALIDADE EM CIÊNCIA DA INFORMAÇÃO
}

\author{
INTERDISCIPLINARIEDAD Y TRANSVERSALIDAD EN CIENCIA DE LA \\ INFORMACIÓN
}

SILVA, Terezinha Elisabeth da (Org.). Interdisciplinaridade e transversalidade em Ciência da informação. Recife: Néctar, 2008. 216p. ISBN: 978-85-60323-16-6.

A interdisciplinaridade surge no século $X X$ como um esforço de superar o movimento de especialização da ciência e superar a fragmentação do conhecimento em diversas áreas de estudo e pesquisa. Fortalecida logo após a segunda guerra mundial, momento em que historicamente as raízes da Ciência da Informação tambem se firmam. Talvez esteja neste movimento pós-segunda guerra a explicação para o paradigma da interdisciplinariedade da Ciência da Informação explorado fortemente por inúmeros pesquisadores da área, como Saracevic; Capurro; Hjørland; Wersig; Le-Coadic; Braga; Gonzalez de Gomez, entre outros.

A transversalidade é a possibilidade de se criar pontos comuns entre aprender conhecimentos teoricamente sistematizados e as "questões da vida". Segundo Amélia Hamze, professora e colunista do Brasil Escola, por esse enfoque, deve-se possuir uma visão mais ampla, acabando com a fragmentação do conhecimento, pois somente assim se apossará de uma cultura interdisciplinar. A transversalidade e a interdisciplinaridade são modos de trabalhar o conhecimento que buscam reintegração de procedimentos acadêmicos, que ficaram isolados uns dos outros pelo método disciplinar. Piaget sustentava que: "a interdisciplinaridade seria uma forma de se chegar à transdisciplinaridade, etapa que não ficaria na interação e reciprocidade entre as ciências, mas alcançaria um estágio onde não haveria mais fronteiras entre as disciplinas". 
Na obra de Michael Gibbons em conjunto com outros autores, intitulada The new production of knowledge publicada em 1994, são apresentados argumentos que indicam uma nova forma de produção do conhecimento que começou a surgir a partir de meados do século 20 e que envolve equipes multidisciplinares reunidas para trabalhar sobre problemas específicos. A obra trás duas formas de produzir o conhecimento, chamadas modo 1 e modo 2. No modo 1 a produção de conhecimentos é baseada no pesquisador e tem uma disciplina como base, enquanto no modo 2 esta produção é centrada nos problemas e na interdisciplinaridade - poderíamos acrescentar - e também na transversalidade, uma vez que os autores fortalecem a importância de considerarmos as possibilidades do mundo real e é neste ambiente onde surgem as demandas transversais que perpassam pelos conteúdos disciplinares.

A obra aqui resenhada foi publicada em 2008, trata-se de uma coletânea organizada por Terezinha Elisabeth da Silva, Doutora em Multimeios pela Universidade Estadual de Campinas (UNICAMP), atualmente professora adjunto do Departamento de Ciência da Informação da Universidade Estadual de Londrina (UEL), docente do Curso de Graduação em Biblioteconomia e do Mestrado Profissional em Gestão da Informação.

Dividida em duas partes, sendo a primeira com conteúdo relacionado a pesquisas teóricas e a segunda com pesquisas empíricas, a obra forma ao final da leitura a possibilidade de reflexão sobre os caminhos - muitas vezes surpreendentes - seguidos pela Ciência da Informação.

Na sessão nomeada sobre os autores são apresentados resumos dos currículos dos vinte e dois colaboradores, entre docentes e outros profissionais ligados a Ciência da Informação, responsáveis pelos oito capítulos divididos simetricamente nas duas partes supracitadas. É também importante dizer que em uma análise furtiva desta sessão pôdese perceber por meio das ocupações e formações profissionais destes autores a contribuição para o conteúdo interdisciplinar e transversal da obra.

Já na apresentação da obra vale ressaltar as palavras da organizadora "o que há de central nesta coletânea é a capacidade que tem a Ciência da Informação - em seus estudos e praticas - de se multiplicar, atendendo as demandas que emergem em razão de sua própria configuração enquanto área do conhecimento. Com esta junção de estudos - de maneira não concorrente - pretendemos mostrar que não há oposição entre eles, que não há hierarquia. São formas e opções diferentes e complementares de expor as várias facetas de nossa área de atuação e pesquisa." (Apresentação, p.10).

A parte 1 referente às Pesquisas Teóricas tem seu inicio com o capitulo intitulado Algumas reflexões filosóficas sobre a memória no ciberespaço de autoria de Silvana 
Drumond Monteiro e de Ana Esmeralda Carelli ambas as professoras Doutoras da Universidade Estadual de Londrina (UEL), que deixam a contribuições da filosofia impressa á obra.

Sob o titulo Clima organizacional para implantação de política de gestão documental em sistemas de arquivos universitários encontram-se as contribuições de Nádina Aparecida Moreno professora Doutora da Universidade Estadual de Londrina e de Maria Emilia Sigoli Marques, arquivista e atualmente chefe da divisão de arquivo intermediário do Sistema de Arquivo da UEL (SAUEL) coube a elas as contribuições da arquivologia.

Em Mediação da informação e da leitura têm-se as reflexões maduras sobre o assunto de Oswaldo Francisco de Almeida Junior, professor Doutor da Universidade Estadual de Londrina e da pós-graduação em Ciência da Informação da UNESP em Marília - SP, em co-autoria de Sueli Bortolin professora Mestre da Universidade Estadual de Londrina e Doutoranda em Ciência da Informação na UNESP em Marília - SP, colaboração que aborda a leitura.

No capitulo Competências informacionais no uso de bibliotecas digitais como apoio ao Ensino a Distância, Maria JuliaGiannasi-Kaimen, professora Doutora da Universidade Estadual de Londrina e Vilma Aparecida Gimenes da Cruz, professora mestre da UEL, atualmente aposentada pela mesma e atuando na Universidad Norte do Paraná (UNOPAR) trazem suas reflexões sobre a competência informacional necessária no uso de bibliotecas digitais no Ensino a Distancia (EaD).

A segunda parte referente ás Pesquisas Empíricas tem seu inicio com Sistema de inovação em alimentos funcionais, capítulo que trata de análise das fontes informacionais de redes de cooperação no Estado do Paraná, tendo como tema os alimentos funcionais. Apresenta a contribuição de sete co-autores: Maria Inês Tomaél, professora Doutora da Universidade Estadual de Londrina atua na graduação em Biblioteconomia e no Mestrado Profissional em Gestão da Informação; Adriana Rosecler Alcará, bibliotecária e mestre em educação é professora da Universidade Estadual de Londrina; Elaine Cristina Liviero Tanzawa, bibliotecária e mestranda em Educação pela UEL; Ivone Guerreiro Di Chiara professora mestre da Universidade Estadual de Londrina; Plínio Pinto de Mendonça Uchoa Junior, Engenheiro Agrônomo Doutor em tecnologias de alimentos é professor visitante no Instituto de Estudos Avançados de São Carlos-SP; Sulamita da Silva Valente, bibliotecária pesquisadora da área de negócio em informação tecnológica (NTI); e Valéria Cristina Heckler Piedade, Bibliotecária do NTI e do Centro de Tecnologia da Madeira e Mobiliário (SENAI/CETMAM). 
A organizadora da obra, Terezinha Elisabeth da Silva, em conjunto com a bacharel em Biblioteconomia pela UEL, Luana Priscila Costa, produziram o capitulo intitulado Repositórios multimídia: estrutura hipertextual e avaliação hipermidiatica que trás contribuições para repositórios multimídia destacando as peculiaridades hipertextuais e hipermidiáticas.

Em Informação e comunicação no âmbito das praticas umbandistas, Linete Bartalo, Doutora em Educação pela UNESP/Marilia e professora da Universidade Estadual de Londrina; Maria Letícia Rosa Premuli, acadêmica do curso de graduação em biblioteconomia da UEL; Silvana Maria da Silva, bibliotecária formada pela UEL; e Cláudio Müler que é Umbandista e mestre em Biologia Vegetal, analisam a contribuição da literatura especifica na pratica religiosa, neste capitulo representada pela Umbanda.

Por fim, no artigo intitulado Acessibilidade digital e as pessoas com deficiência visual associadas à Adevilon, de autoria de Rosália Ferreira, bibliotecária pela UEL que desenvolveu seu Trabalho de Conclusão de Curso (TCC) sobre este tema e de Sueli Bortolin, professora Mestre da Universidade Estadual de Londrina e Doutoranda em Ciência da Informação na UNESP em Marília - SP, contempla-se a acessibilidade digital do ponto de vista dos portadores de deficiência visual.

Assim como descrito na obra de Gibbons sobre o Modo 2, esta produção é centrada em problemas de pesquisas reais e na interdisciplinaridade como forma de resposta juntamente com a transversalidade do cotidiano das pesquisas acadêmicas, sejam elas teóricas ou empíricas.

Boa Leitura!

Elaine R. de Oliveira Lucas lani@udesc.br Departamento de Biblioteconomia e Gestão da Informação Universidade do Estado de Santa Catarina - UDESC

\section{Title}

Interdisciplinarity and transversality in Information Science

\section{Titulo}

Interdisciplinariedad y transversalidad en Ciencia de la Información 